\section{Malária entre populações indígenas do Brasil}

\author{
Dalva A. Mello*
}

"A feição deles é serem pardos, um tanto avermelhados, de bons rostos e narizes bem feitos... e certo era tam bem feito e tam redonda, de sua vergonha tam graciosa que a muitas mulheres de nossa terra vendo-lhes tais feiçōes, envergonhara, por não terem as suas como ela". Carta de Pero Vaz de Caminha. Hoje, sexta-feira, primeiro dia de Maio de 1500. Deste Porto Seguro da Vossa Ilha de Vera Cruz.

In the current paper the Author describes the situation of malaria among the aboriginal natives of Brazil since the colonial times. Attention is called to the scanty scientific information on a subject of so much relevance for this country.

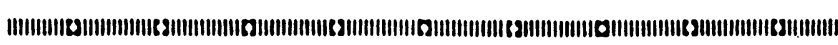

Malária é ainda uma das parasitoses humanas de maior distribuição geográfica. Calcula-se que, anualmente, cerca de 200 milhões de indivíduos são acometidos pelo paludismo. Em decorrência de seus altos índices de morbidade, prevalência, letalidade, constitui uma das mais importantes doenças do mundo.

Autóctone da Ásia e África, a malária foi trazida para o continente americano pelos colonizadores europeus. Das quatro espécies de parasitas responsáveis pela malária humana, três foram introduzidas neste continente, a saber: Plasmodium vivax, $P$. falciparum e $P$. malariae.

O período explosivo de descobertas de novas terras no Novo Mundo pelos Europeus - séculos XV - XVI - teve sem dúvida profundo efeito no padrão de saúde das populações indígenas. $\mathrm{O}$ homem europeu trouxe consigo e impôs, além de seus valores culturais e sociais, suas doenças endêmicas, hábitos alimentares, que influíram diretamente no vigor físico e psíquico dessas populações.

$\mathrm{Neel}^{26}$ reforça essa colocação, quando ressalta que está bem documentado o quadro de saúde exuberante pelas populações ameríndias, quando se iniciou o contato com os "brancos" e, da mesma maneira, sua rápida deterioração. A este aspecto vale citar tex tualmente, Ribeiro ${ }^{29}$, quando fala sobre a expansão do domínio europeu nas Américas:

"A todos estes motores se somaria, como uma das armas decisivas da conquista, um conglomerado de vírus, bacilos e germes, a que os povos europeus, asiáticos e africanos esta-
- Departamento de Ciências da Saúde - Universidade de São Carlos, São Carlos, SP 
vam adaptados, mas que se abateram sobre os povos indenes da América e da Oceania, como novas pragas bíblicas, tornando-os inermes à agressão e à sujeição. Calcula-se que, logo após os primeiros encontros com homens brancos, morreu infectada a metade e, por vezes, três quartas partes da população aborígene americana, australiana e das ilhas oceânicas, vitimadas por moléstias pulmonares, por infecções venéreas, pela sífilis, pelas diversas variedades de varíola e por mais de uma dezena de outras enfermidades que desconheciam". Ainda Ribeiro ${ }^{30}$ chama a atenção para o fato de que as doenças introduzidas nas populações indígenas pelo migrante europeu "constituíram sempre o primeiro fator de queda da população... A história das nossas relações com os índios é, em grande parte, uma crônica de chamas e sobretudo de epidemias". Este autor salienta que as doenças levadas aos índios pelos colonizadores constituíram importantes elementos dissociativos de depopulação. „A exceção da micose de Jorge Lobo ${ }^{22}$, do chimberề, 28 e da treponematose responsável pela pinta ${ }^{2}$, as demais entidades mórbidas infecciosas, de gravidade clínica, foram introduzidas nas populações indigenas pelos "civilizạdos":

Entre numerosos agentes etiológicos (vírus da varíola, sarampo e gripe, bactérias intestinais e das vias respiratórias), aqueles responsáveis pela malária principalmente $-P$. falciparum e $P$. vivax - contribuíram e ainda contribuem, substancialmente, ao quadro de morbidade das populações indígenas do Brasil.

Estudos científicos que analisem a șituação epidemiológica da malária entre as populações indígenas do Brasil são escassos. De uma maneira geral, as informações estão restritas ao número de casos descritos nos relatórios do antigo Serviço de Proteção ao Indio (SPI), da atual Fundação Nacional do Indio (FUNAI) e Conselho Missionário Indigenista (CIMI).

Em 1896, Karl E. Ranke, visitando o Xingu juntamente com $\mathrm{H}$. Meyer, verificou numerosos casos de malária numa população de 800 a 1.000 habitantes. Era então a doença "responsável por maior mortalidade, sobretudo entre as crianças". Este autor relata a emotividade da aldeia em relação aos sintomas clínicos (caquexia, baços tumefactos) e o trabalho do pagé na tentativa de debelá-los inutilmente. Nesta época, calcula Ranke que havia no Xingu uma população de três a quatro mil índios, distribuídos em 39 aldeias, enquanto em 1952 restavam apenas 652, distribuídos em 30 aldeias $^{30}$.

Ribeiro $^{30}$ menciona dados de relatórios do SPI sobre malária entre os Botocudos e os Xokleng, tribos que viviam respectivamente nos estados do Espírito Santo e de Santa Catarina. A malária, junto com a coqueluche e a gripe, contribuiu para a queda vertiginosa da população dos Kokleng. Este grupo, quando pacificado em 1914, era cons- 
tituído por cerca de 800 indivíduos, estando reduzido para 89 , nos dias atuais.

Atualmente, os grupos indígenas em que a malária está melhor estudada encontram-se no Parque Nacional do Xingu (PNX). Estes grupos estão em contacto intermitente com a "civilização" i.e., as relações com o "branco" estão restritas ao pessoal da FUNAI, missionários e alguns pesquisadores. No PNX, a Escola Paulista de Medicina desenvolve um programa de medicina preventiva, o qual vem minimizando certos problemas de saúde que ocorrem na área. E, entre as doenças prevalentes na população indígena do PNX, para as quais tem sido dirigida especial atenção médica, estão as das vias respiratórias e a Malária ${ }^{4}$.

No PNX, a transmissão dos parasitas da malária é intensa, ocorrendo durante todo o ano, com pequenas flutuações. Baruzzi ${ }^{3}$ verificou que existem no PNX duas espécies de mosquitos transmissores dos parasitas de malária: Anopheles darlingi e $A$. albitarsis. A segunda espécie é encọntrada fora das habitações, e a primeira, considerada o vetor mais importante, é encontrada tanto dentro das malocas, quanto no exterior. Este autor, estudando os grupos indigenas que habitam o Alto Xingu, verificou no exame físico 66 casos de hepatomegalia acompanhada também pelo aumento do baço. Os resultados referentes a 127 índios examinados mostraram a infecção por parasitas da malária em 70 , com a seguinte distribuição: $47,7 \%$ infectados por $P$. vivax; $35,8 \%$ por $P$. falciparum e $16,4 \% P$. malariae. Três indivíduos tinham infecção mista pelas duas primeiras espécies. Estudos posteriores no PNX, conduzidos por Baruzzi et alii ${ }^{5}$, mostraram que a chamada "Síndrome de Esplenomegalia Tropical" era aí bastante freqüente, tendo sido diag. nosticada em 33\% de 730 indivíduos examinados. Entre 1968-1973, Baruzzi et alii ${ }^{5}$ verificaram que, entre 22 adultos que morreram no PNX, a causa "mortis" em 7 foi devida a episódios de hematemesis e melena, provavelmente por rutura de varizes gastrointestinais, resultante de complicações desta síndrome. A presença de Plasmodium spp foi diagnosticada em $14,3 \%$ da população estudada, enquanto a sorologia mostrou $98,7 \%$ de positividade, indicando assim o contacto constante com os parasitas. $\mathrm{Na}$ primeira quinzena de julho de 1976, novo levantamento foi realizado por Dias \& Baruzzi ${ }^{12}$, desta vez tomando como amostra 7 indivíduos (200 população total), do grupo etário de 2-9 anos (37 do sexo masculino e $3 \dot{4}$ feminino). $O$ índice total da infeç̧ão diagnosticada pela presença de parasitas no sangue foi $11,3 \%$, enquanto o índice esplênico foi de $44,4 \%$.

Quando os Kreen-Acarore foram transferidos para o PNX, Baruzzi et alii ${ }^{6}$ acompanharam a evolução de alguns aspectos da saúde desta tribo. Em janeiro de 1976, os 75 Kreen-Acarore remanescentes da população original (140 indivíduos), quando contactada em 1975, foram transporta- 
dos para o PNX. Em julho de 1976, restavam apenas 64 sobreviventes. Os resultados do exame físico mostraram hepatomegalia associada a esplenomegalia, sendo bastante indicativo da síndrome acima citada. 0 estado de saúde dos Kreen-Acarore foi acentuadamente agravado pela infecção concomitante de malária e ancilostomose, somados à escassez de alimentos. Assim é que, de 11 indios doentes de malária, 5 vieram a falecer. Os anticorpos pesquisados para esta parasitose foram detectados em $100 \%$ da população restante dos Kreen-Acarore.

Black et alii ${ }^{7}$ trabalharam com sete grupos que vivem no baixo Amazonas: Tiriyo, Ewarboyan, Kaxuyana, Xikrin, Gorotire, Kuben-Kran-Kegn, Mekranoti. Esses grupos são caçadores e coletores, porém variam quanto à duração e grau de contacto com a civilização. Os Ewarboyan, KubenKran-Kegn e Tiriyo vivem na savana, nas bordas das matas ciliares. Os outros vivem na floresta. As pesquisas conduzidas por esses autores, para malária, foram baseadas na palpação do baço e em exame de sangue para pesquisa dos parasitas. Entre 299 indivíduos examinados (114 Xikrin e 185 Mekranoti), 19\% tinham baço palpável (41 - Xikrin e 6 Mekranoti). $O$ indice esplênico foi mais baixo entre os Mekranoti do que nos Xikrin. Os dados epidemiológicos sugerem que a malária entre os Xikrin seja mesoendêmica e entre os Mekranoti hipoendêmica.

Ferraroni \& Hayes $^{13},{ }^{14},{ }^{15}$ e Ferraroni \& Lacaz ${ }^{16}$ estudaram malária entre os seguintes grupos indígenas: os Munducuru, grupo que, embora mantenha contacto com a "civilização" há mais de 40 anos, permanece ainda em certo grau de isolamento; os Mayongong, grupo semi-nômade, que mantém contacto esporádico com os "brancos"; e os Sanomã, grupo indígena de recente contacto. Foram obtidas amostras de sangue dos Mayongong e Sanomã na época da estação seca e dos Munducuru, na época da estação chuvosa. Exames sorológicos, utilizando-se a imunofluorescência indireta, mostraram na população estudada positividade em $17,3 \%$ dos Munducuru, $80 \%$ entre os Mayongong e $77,7 \%$ dos Sanomã. A parasitemia patente por $P$. falciparum foi detectada em $39 \%$ da população dos Mayongong e $26 \%$ dos Sanomã. A faixa etária mais afetada foi entre 20-29 anos, justamente aquela de maior mobilidade nas aldeias. A única espécie de transmissor, $A$. darlingi foi capturada nas imediações da área habitada pelos Mayongong. Ferraroni \& Hayes $^{13}$ e Charlwood \& Hayes ${ }^{8}$ estudaram aspectos comportamentais de $A$. darlingi capturados nessa região, verificando picos de população no final de estação seca. Esses achados foram semelhantes àqueles encontrados por Hayes \& Charlwood ${ }^{19}$ e Hayes \& Ferraroni ${ }^{20,21}$ em áreas de serra do norte de Manaus (BR 174), sendo, no entanto, o inverso daqueles encontrados em áreas baixas de $\mathrm{Be}$ lém ${ }^{11,18,31}$. 
Os Karajás compreendem outro grupo indígena em que a situação da malária é bastante crítica, como chama atenção para este fato a pesquisadora $\operatorname{Costa}^{10}$. Os primeiros contactos dos Karajás com os "civilizados" ocorreram nos fins do século XVI e início do século XVII. Nessa época começaram a chegar ao vale do Araguaia-Tocantins, região aonde viviam os indígenas, os Bandeirantes que, procedentes de São Paulo, buscavam escravos índios e ouro e, em troca, introduziam, por sua vez, agentes mórbidos até então desconhecidos a esses grupos. José Pinto da Fonseca, citado por essa autora, ao visitar a Itha do Bananal em 1773, calculou que havia então cerca de 9.000 índios espalhados em nove grandes aldeias. Atualmente a população Karajás está reduzida a cerca de 1.000 indivíduos, redução esta decorrente de, entre outros fatores, aqueles ligados a ações de agentes mórbidos tais como, a malária, tuberculose, sarampo, etc.

\section{CONSIDERAÇÕES FINAIS}

No Brasil, desde os tempos da colônia, como testemunham numerosos escritos, documentos e relatórios, constituiu a malária notória doença de preocupação das autoridades. Esta parasitose dizimou aqui grandes contingentes populacionais. Foi, portanto, e ainda é, sério problema para o país no campo da saúde pública. Peixoto ${ }^{28}$, ao estudar o problema sanitário da região Amazônica, ressal ta o seguinte em relação a esta endemia: "É a malária, só ela, a causa da devastação sem precedentes que assola aquelas regiões e thes dá fama sinistra. Levas e levas de imigrantes que a cobiça conduz pelos seus rios, ao recesso de suas florestas, nenhum escapa ao ataque; o maior número, senão todos, às vezes, não escapa à morte. Salvam-se acaso os que fogem, se não vêm a morrer pelo caminho". Ainda Peixoto ${ }^{28}$, ao situar historicamente esta endemia, relata que, na baixada amazônica, onde a situação era bastante grave, só foi denunciada pela segunda metade do século XIX: "hoje, mosquitos e impaludados tornam as regiões às vezes insalubres, e o problema tem tal importância que deve ser considerado à parte". "As crônicas coloniais não falam dela e os viajantes, até o meado do século XIX, dela não se ocupam". O problema foi sem dúvida agudizado com as grandes correntes migratórias que a esta região se dirigiram, provenientes de toda a parte do Brasil. E a história da malária fica célebre quando, na construção da estrada de ferro Madeira-Mamoré, foi a responsável pela derrota de duas firmas que assumiram a responsabilidade do empreendimento desta grande obra. A malária então caiu como uma verdadeira hecatombe sobre essas regiões do Brasil. Cita Batista ${ }^{32}$ o seguinte relato de Oswaldo Cruz, nessa época, sobre a situação na Amazônia.. "está de tal modo infectada, que sua população não tem noção do que seja estado hígido e para ela a condição de ser enfermo constitui a normalidade... E há o impalu- 
dismo, moléstia evitável, o único terror sério destas regiōes".

Peixoto ${ }^{28}$ mostra a malária como sendo doença responsável, em 6\% lugar, pelos óbitos do Rio de Janeiro. Os coeficientes de mortalidade por malária citados por este autor, para algumas capitais do Brasil, em 1936, eram: Manaus 545,2; Belém - 162,9; Fortaleza - 40,7; Recife - 8,2; Maceió - 139,0; Bahia - 135,0; Rio - 14,5. Em 1940, 1/7 da população brasileira adoecia, anualmente, de malária. $\mathrm{E}$, até 1946, à exceção do sertão nordestino e de regiōes de altitudes acima de 800 metros, a malária se expandia por todo o país.

A partir da descoberta do DDT e dos antimaláricos sintéticos, e, ainda, com a execução de grandes obras de saneamento e drenagens, foi possível reduzir no Brasil as áreas de transmissão de malária. Nestas, incluíam-se os estados do nordeste oriental, a região do triângulo mineiro, sudeste e sul do pais. No entanto, apesar desses esforços, a malária ainda continua no presente incidindo em extensas regiões do país, principalmente na Amazônia. Esforços têm sido conduzidos por parte das autoridades sanitárias, no sentido de debelar a malária na região Amazônica. Apesar disso, constituindo esta região sempre área-problema no controle desta parasitose, é exatamente aí que, a partir de 1975, tem havido um incremento gradual do número de pessoas infec$\operatorname{tadas}^{24}$.

Toda a Amazônia vem recebendo o impacto de grandes programas desenvolvimentistas. Dessa forma, vários municípios da Amazônia Legal são cenários de implantação de grandes projetos agropecuários, os quais atraem numerosos contingentes migratórios de regiões não mais endêmicas. Assim, populações humanas, sem nenhuma resistência aos parasitas e sem qualquer outro tipo de proteção, vão ser alvo, como no passado, de infecções maciças e constantes dos surtos epidêmicos de malária. Do total de lâminas examinadas e positivas - 97.960 em 1977 e 195.937 em $1981^{27}$ $80 \%$ têm sido procedentes desta região. Por sua vez, é constatado que o maior número de casos está localizado ao longo das rodovias em construção, projetos agropecuários e garimpos 23,24 . Acrescente-se ainda que os problemas em relação à malária adquirem mais outra feição, quando se constata a reintrodução da parasitose nas regiões em que ela foi controlada ou erradicada. Esses problemas de natureza eminentemente social decorrem, entre outros fatores, do fato de que, não encontrando trabalho, grandes contingentes humanos que vão à Amazônia e retornam às suas origens, muitas vezes doentes, portadores dos parasitas, reintroduzem a doença onde já havia sido debelada.

A consecução do programa de controle de malária no Brasil vem recebendo interferência de modo marcante de numerosos e complexos problemas, entre os quais citam-se 
aqueles ligados à resistência dos parasitas à terapêutica, desconhecimento dos hábitos dos vetores, aspectos de ecologia humana, pobreza, privação social e analfabetismo ${ }^{33}$. A estes, ainda, somam-se aqueles de natureza administrativa, como contenção de verbas e pessoal qualificado. Gabaldon ${ }^{17}$, pesquisador de grande experiência no assunto, ressalta que as dificuldades na erradicação da malária estão principalmente ligadas ao estágio de desenvolvimento do país. No Brasil, o próprio Ministério da Saúde admite: "Mais do que uma coincidência, é uma realidade o fato de que aonde a malária se apresente em alta endemicidade, com ela estão o atraso econômico, a pobreza, a fome e doenças carenciais ${ }^{9}$ ".

De acordo com a classificação da Organização Pan-Americana da Saúde, o Brasil, juntamente com o Equador, México, Suriname e Venezuela, caracteriza-se por desenvolver atividades de combate à malária a nível nacional (Grupo III). Segundo Marques ${ }^{24}, 43,2 \%$ da população total das áreas malarígenas das Américas estão situados nesses países.

Assim, pelo que foi exposto e retomado o tema central deste artigo, conclui-se que a situação presente da malária entre as populações indigenas do Brasil está intimamente associada à problemática da endemia nas populações "brancas". Ressalta-se, mais uma vez, que nas regiões onde vivem grupamentos indígenas não existem estudos suficientes para caracterizar e avaliar o quadro epidemiológico particular a cada área. Chama-se a atenção para o fato de que é na Amazônia, região de mais alta endemicidade da malária, onde está concentrada a maior parte da população indígena do país, estimada atualmente em torno de 70-100 mil indivíduos, divididos em 143 grupos tribais ${ }^{25}$.

Existem possibilidades de melhorar as ações contra a malária, como ressalta Acunã ${ }^{1}$, desde que se aprofundem os estudos epidemiológicos e se distribuam melhor os recursos existentes, fazendo uso de maneira efetiva e racional dos serviços de saúde, i.e., integrando o programa de controle às estruturas dos serviços primários. Ao lado destas recomendações, é importante chamar a atenção para a necessidade de pesquisas, para melhor conhecimento de vários aspectos da epidemiologia da malária na região amazônica. Estes estudos deveriam contribuir com resultados que indicassem novas alternativas no controle desta parasitose, uma vez que os métodos clássicos já não atendem satisfatoriamente ao problema. Tudo isso, no entanto, não é novidade, ao ser lembrada aqui a mesma preocupação de Oswaldo Cruz, expressa em seu relatório sobre a situação da Madeira-Mamoré em 1913 “... há expressa recomendação da intensificação de trabalhos de pesquisa de medicina experimental, para esclarecerem os problemas que esperam solução ${ }^{32}$ ". Acrescento ainda que, em se tratando de áreas de conflitos interculturais, pesquisas de cunho antropológico, em especial 
aquelas calcadas na antropologia médica, são de fundamental importância.

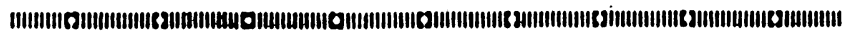

No presente trabalho a Autora descreve a situação da malária entre populações indigenas do Brasil, desde a época colonial até o momento presente, enfatizando a falta de informações cientificas sobre assunto de tanta relevância para o pais.

\section{REFERÊNCIAS BIBLIOGRÁFICAS}

1. ACUNÃ, H.R. Necessidad de cambios de la lucha contra la malaria. Bol. Of. Sanit. Panam., 85 (6) :377-8, 1978.

2. AQUINO, U.M. Pinta no Alto Solimões; 30 casos observados na tribo Ticuna. Rio de Janeiro, 1974. [Tese de Livre-Docência - Faculdade de Medicina - UFRJ].

3. BARUZZI, R.G. Contribuição para o estudo epidemiológico da toxoplasmose; levantamento sorológico em índios do al to Xingu, Brasil Central. São Paulo, 1968. [Tese de Doutoramento - Escola Paulista de Me dicina] .

4. BARUZZI, R.G. \& FRANCO, L. Ameridians of Brazil. In: TROWELL, H.C. \& BURKITT, D.P., ed. Western diseases: their emergence and prevention. s. 1., Arnold Publ., 1981.

5. BARUZZI, R.G. et alii. The association between splenomegaly and malaria in Indians from the Alto Xingu, Central Brazil. R. Inst. Med. trop. S. Paulo, 18 (5) :322-48, 1976.

6. BARUZZI, R.G. et alii. The Kren-Akorore; a recently contacted in digenous tribe. Ciba Found. Sym. Health Dis. Tribal Soc., $49: 179-211,1977$.

7. BLACK, F.L. et alii. Evidence for persistence of infections agents in isolated human populations. Am. J. Epidemiol., 100 (3) :230-50, 1974.

8. CHARLWOOD, J.D. \& HAYES, J. Variações geográficas no ciclo da picada do Anopheles darlingi no Brasil. Acta Amaz., $8: 601-3,1979$.

9. CONFERENCIA NACIONAL DE SAÚDE, 5. Brasília, 1975. Anais. Brasília, Ministério da Saúde, 1975.

10. COSTA, M.H.F. A arte e o artista na sociedade Karajá. Brasília, DGPC-DEP, FUNAI, 1978. 
11. DEANE, L.M. et alii. Notas sobre a distribuição e a biologia dos anofelinos das regiões nordestinas e amazônica do Brasil. R. Serv. esp. Saúde Públ., 1 (4) :827. 966, 1948.

12. DIAS, L.C.S. \& BARUZZI, R.G. Prevalence of malaria in Indians of Xingu Indian Reservation (Brasil). Trans. R. Soc. Trop. Med. Hyg., 72 (2) :210, 1978.

13. FERRARONI, J.J. \& HAYES, J. Aspectos epidemiológicos da malária no Amazonas. Acta Amaz., $9: 471$. 9, 1979.

14. FERRARONI, J.J. \& HAYES, J. Drug resistence falciparium malaria among the Mayongong Indians in the Brazilian Amazon. Am. J. Trop. Med. Hyg., 28 (5) :909-11, 1979.

15. FERRARONI, J.J. \& HAYES, J. Estudo sobre um surto de malária entre índios Mayongong e Sanomã (Norte de Roraima). Acta Amaz., 7 :401-6, 1977.

16. FERRARONI, J.J. \& LACAZ, C. da S. Prevalência de anticorpos contra os agentes causadores de hepatite, malária, sífilis e toxoplasmose em cinco populações humanas distintas da Amazônia brasileira. R. Inst. Med. trop. S. Paulo, 24 (3) :155-61, 1982.

17. GABALDON, A. Difficulties confronting malaria erradication. Am. J. Trop. Med. Hyg., 21 (5) :634-9, 1972.

18. GALVÃO, A.L.A. et alii. Algumas observações sobre a biologia dos anofelinos de importância epidemiológica de Belém. Arq. Hig., 12 (2) :51-111, 1942.

19. HAYES, J. \& CHARLWOOD, J.D. Dinâmica estacional de uma população de Anopheles darlingi, numa área endêmica de malária no Amazonas. Acta Amaz., 9: 79-86, 1978.

20. HAYES, J. \& FERRARONI, J.J. Malaria along pioneer highways in the Brazilian Amazon, Ci. Cult., 33 (7): 924-8, 1981.

21. HAYES, J. \& FERRARONI, J.J. Ocorrência de malária numa estrada recém-construída no Amazonas. Acta Amaz., $8: 397-407,1978$.

22 LÔBO,J. Nova espécie de blastomicose. Bras. Med., 44 : 1.327, 1930.

23. MARQUES, A.C. Migrações e grandes endemias. $R$. bras. Malariol. D. trop., 31 :137-58, 1979.

24. MARQUES, A.C., comp. Situação atual da malária no mundo. R. bras. Malariol. D. trop., 32 :73-83, 1980.

25. MELATTI, J. Índios do Brasil. Brasília, Ed. Univ. de Brasília, 1970. 
26. NEEL, J.V. Control de las enfermedades de los amerindios en transición cultural. Bol. Of. Sanit. Panam., 77 (6) :478-85, 1974.

27. ORGANIZAÇÃO PAN-AMERICANA DA SAÚDE. Seminário sobre treinamento em malária. Washington, 1982. mimeo.

28. PEIXOTO, A. Clima e saúde. São Paulo, Cia. Ed. Nacio nal, 1938. 295 p. [Brasiliana. Ser. 5, Biblioteca Peda gógica Brasileira, 129].

29. RIBEIRO, D. As Américas e a civilização; estudos de antropologia da civilização. Rio de Janeiro, Vozes, 1977.

30. RIBEIRO, D. Os indios e a civilização; a integração das populações indígenas no Brasil moderno. 3. ed. Rio de Janeiro, Vozes, 1979.

31. SILVA, R.A. da. Malária: clínico, epidemiológico na recente colonização agrícola da região Oriticupu, no estado do Maranhão. Rio de Janeiro, 1975. [Tese de Mestrado - Faculdade de Medicina - UFRJ] .

32. SOBRE o saneamento da Amazônia. Manaus, P. Daou, 1972.

33. WESSEN, A.F. Human ecology and malaria. Am. J. Trop. Med. Hyg., 21 (5) :658-62, 1972. 